\title{
Muestra Mexicana de Teatro 2007
}

\section{Enrique Mijares}

El balance de la Muestra Nacional de Teatro realizada recientemente en Zacatecas confirma lo que sin duda Ignacio Escárcega, titular de la Coordinación Nacional de Teatro del INBA, había previsto desde el inicio. Hubo espectáculos de todo y para todos. De calle, rubro en el que dicha ciudad es experta merced al Festival Internacional de esa categoría que realiza cada año y que atraen masivamente a la comunidad: Piedras de la fe de Oaxaca y Las mil y una noches de la sede. Para niños y jóvenes: Arlequín servidor de dos amos que inauguró el evento, Hansel y Gretel que lo clausuró, además de El rey que no oía pero escuchaba, los tres validando el canon binario, pretendidamente didáctico, más dos montajes provistos de innovadores códigos de lenguaje: La niña de Tecún y No tocar. Y hasta nocturnos de los que gustan el público desvelado de la Muestra y algunos parroquianos locales: Copelas o cuello ópera china pirata, Yo en una cantina?, Improvisados y medio, La Iliada versión 7.3. ¡Hubo incluso Noche de Karaoke!

En fin. Obras bajo el régimen de coproducción, obras seleccionadas por convocatoria, obras invitadas, obras de grupos emergentes, espectáculos nocturnos, cursos, talleres, presentaciones de libros y revistas, exposiciones y, como plato fuerte entre las actividades académicas, la conferencia magistral de Ricard Salvat, presidente de la Asociación de Investigación y Experimentación Teatral de Barcelona.

Propuse y aplaudí hace varios años el nacimiento de las coproducciones con la intención de que los creadores regionales tengan la posibilidad de realizar aquellos proyectos que han soñado. Sin embargo la mecánica de selección en numerosas ocasiones se ha visto viciada cuando los montajes provienen apoyos de otro tipo y de ciclos anteriores, o cuando se otorgan para favorecer tal o cual proyecto de tal o cual director que no corresponde a la comarca, y cuyos resultados, para colmo, no han cubierto las expectativas. 
Decepcionó en esta ocasión que se redujeron a tres los espectáculos (apenas el quince por ciento de la programación) a los cuales se brindó subsidio mancomunado de la federación y de sus estados: Zacatecas, Yucatán y Nayarit, con resultados cuestionables tanto de teatralidad propiamente dicha, como extra teatrales, debido principalmente a que de manera invariable los agraciados no superan la presión de tener que evidenciar ante las autoridades el recurso financiero que les han otorgado, por lo que es común ver soluciones grandilocuentes o artefactos descomunales e inútiles formando parte del dispositivo escénico.

Así, las esperanzas que hizo concebir la coproducción dirigida por el nayarita, regiomontano por adopción, Carlos Gueta, con el estreno de la obra Cielo rojo del morelense Alejandro Román - quien por cierto lleva tres importantes premios nacionales consecutivos en menos de un año: el Oscar Liera de Sinaloa por Línea de fuego; el Sánchez Mayans de Campeche por La misa del gallo, y el de la UANL por el texto mencionado -, zozobraron en medio de un palenque construido por tablas y láminas de segunda que parecían haber sido recogidas del basurero por el escenógrafo argentino Jorge Ferro con aviesas intenciones: para no afectar al presupuesto, para que el director expusiera al desnudo (y no me refiero a la ropa, aunque llevaban muy poca, sino a los recursos escénicos que no les proporcionó) a su cuarteta de actores en proscenio y para que a los espectadores nos diera tortícolis culiatornillados en una sillería colocada al centro de la pista.

Naufragó doblemente, toda vez que de inundación trata la obra, el aparatoso espejo que la yucateca Conchi León exhibió en su Crónica de un presentimiento, desigual puesta en escena que logró a medias refrendar el éxito rotundo de aquella memorable Mestiza Power, donde el talento le bastó para lograr que su creación de teatro puro fuera considerada la mejor en la Muestra de San Luís Potosí 2005. No es lo mismo dirigir pensando en los espectadores comunes y corrientes, esto es, en el verdadero público, que hacer un espectáculo "por encargo" para complacer a la exigente comitiva de críticos y periodistas que suele asistir a la tradicional fiesta nacional de teatro.

Recordar, por ejemplo, los espectáculos de calle en los que es experto el grupo Cornisa 20 de Celaya Guanajuato me lleva a concluir que Las mil y una noches, dirigida por el colombiano Misael Torres, fue opacada por el churrigueresco entorno arquitectónico de la ciudad sede y no consiguió el despliegue espectacular que prometía. Eso pasa por importar talento extranjero cuando in situ lo hay, mucho y de gran nivel. 
La tercia de coproducciones de esta emisión obliga a revisar el esquema, sobre todo a la hora de empezar a ver en el horizonte la Muestra del 2008, a celebrarse en Ciudad Juárez, Chihuahua. Urge pues una profunda planeación de a quién, para qué, cómo, cuánto y cuándo se habrán de otorgar en lo sucesivo los apoyos de coproducción.

Lo que resulta capital es que no se renuncie a facilitar cada vez más y mejores alternativas a los creadores del interior del país, a fin de que algún día se revierta el constante acaparamiento de la programación por espectáculos provenientes del DF: el treinta por ciento en esta ocasión, todas ellas un monumento a la incontinencia.

Crack de Edgar Chías, dirigida por Martín Acosta: Incontinencia verbal propuesta por el autor y potenciada por los actores: la retórica tepiteña del merolico que le propone el negocio del siglo al desocupado; las aparentemente irreprimibles ganas de orinar de Emma Dipp para enfatizar la adicción a las drogas de su personaje, y la incontinencia de genialidad del director quien utiliza un arnés para poner a volar a dicha actriz con similar propósito. Toda una "jalada" que echa por tierra los esfuerzos creadores de Dana Aguilar y Gabino Rodríguez.

Hipnódromo, trasunto de Casa de muñecas de Ibsen, dirección de José Antonio Cordero: Exceso de soberbia para discernir en qué momento editar los dilatados abismos de inutilidad y de tedio, que son muchos, de los recursos teatrales, que son pocos pero absolutamente creativos, eficaces e incluso inéditos y que poniendo en práctica aquella conseja de sentido común que reza "menos es más," bastarían para conformar un montaje redondo. Sin duda alguien le dijo que el parámetro de la genialidad es la larga duración al estilo Tavira y no le quedó otro remedio que llenar el tiempo muerto con carreritas sin ton ni son de la otrora paradigmática Nora: Mariana Gajá.

Hansel y Gretel, a cargo de Aidé Boeto y Emmanuel Márquez, un musical con vagas referencias a los hermanos Grimm que ni los adultos conseguían soportar, mucho menos los niños, a pesar del abundante dinero que se derrama por la pretenciosa producción al estilo Cirque de Soleil, sin conseguir borrar la esgrima de pastelazos de los "duendes" que "sin ser vistos" acompañan y en ocasiones "precipitan las acciones" de los protagonistas, sin contar con los cánticos teutones que "enmarcan" las torpes coreografías.

Los perros de Elena Garro, cuya directora Sandra Félix, con todos los apoyos financieros a su favor, apenas logra superar la puesta en escena que de la misma obra y menos ínfulas hace Gerardo Moscoso procedente de San Pedro de las Colonias Coahuila. 
Y las dos invitadas por la coordinación teatral del INBA: El rey que no oía pero escuchaba, dirigida por Alberto Lomnitz, con un texto donde la dramaturga Perla Schumacher (integrante de la dirección artística y por tanto juez y parte) valida, una vez más, el canon binario y las soluciones superficiales; y Las chicas del 3.5" floppies de LEGOM, bajo dirección de John Tiffany, un texto anodino con actuaciones providenciales.

Prefiero referirme a las obras procedentes de provincia, característica periférica que siempre ha sido, o debería ser, el rasgo sine qua non de las Muestras Nacionales de Teatro, de acuerdo a la vocación incluyente que al fundarlas les imprimió Pepe Solé.

Notorios desencuentros conceptuales entre los protagonistas de $L a$ noche sucia: el brasileño Augusto Albanés y el cubano Alcibíades Zaldívar representando a la "cosmopolita" Aguascalientes, ciudad que parece no contar con talento local alguno, como si no existiera La Columna, conjunto dirigido por Jesús Velasco, a modo de brillante antecedente.

Noticias del Imperio, de Fernando del Paso, por Querétaro. Abismales diferencias metodológicas entre el regiomontano Ricardo Leal y la queretana Ana Berta Cruces, reincidente en el mismo papel de Carlota y similar dirección de Mauricio Jiménez, nativo de Cuautla Morelos, en aquella controvertida Corona de sombras de Usigli que participó con tan mala fortuna en la Muestra de San Luís Potosí 2005.

De la capital regia acudió Edipo Rey de Sófocles, dirigida por Sergio García. La adaptación reduce el texto hasta el juego elemental de preguntas y respuestas, y los actores acaban sepultándolo.

Los errores del subjuntivo, dramaturgia y dirección de Raquel Araujo, por Yucatán. Estructura audaz, con algunos momentos elocuentes e imágenes poderosas, que el montaje no logra articular.

Piedras de la fe, creación colectiva de Oaxaca: Pasacalle folclórica, de inspiración turística.

Las dos representantes de León Guanajuato: Desiertos en el paraíso dirigida por el venezolano Armando Holser: Un intento por exhumar las puestas itinerantes que estuvieron de moda hace décadas. Impactó a algunos ingenuos y dejó impávidos a la mayoría de escépticos. Arlequín servidor de dos amos, dirigida por Javier Avilés: Vestuario vistoso y trazo escénico puntual al servicio de esa añeja tradición que procede de la picaresca áurea, pasa luego por Molière y Goldoni, y deja a los niños la enseñanza cinematográfica de Cantinflas y la televisiva del Chavo del Ocho. 
Y las dos procedentes de la Universidad Veracruzana: Odio a los putos mexicanos, dirigida por Alba Domínguez y Míriam Cházaro quienes diseñan una dinámica y atractiva puesta en escena para los trabalenguas de la narraturgia de LEGOM que a pesar de la intensión interracial vaciaron la sala a la mitad. Y La niña de Tucún, dirigida por el ensenadense Austin Morgan, adaptación de "La pequeña Tijuana" que poco tiene que ver con el cuento por el que su autora Virginia Hernández recibió el Premio Nacional de Literatura Ciudad de Mérida 2000.

Abundaron las puestas en escena de pequeño formato o de espacios no convencionales porque, según una integrante de la dirección artística "no todo el teatro ha de ser masivo." Tiene razón, los grupos cada vez se inclinan más al modelo alternativo, bien porque carecen de espacio o porque tienen temor de que no haya suficiente público para llenar una sala a la italiana. Por lo pronto, tal modalidad ocasionó conflictos debido a que tanto zacatecanos como muestreros queríamos asistir y no había manera de que los organizadores controlaran la distribución de los boletos de entrada, con el consiguiente enojo de unos y otros. No digo que deba reducirse el número de participantes con estas propuestas, al contrario, en ellas radica mucha de la poca esperanza teatral, toda vez que no se trata del desplante de Margules que ponía a los actores a un paso de los veinte espectadores a fin de que les escupieran el texto a la cara, ni de Tavira que no cree en el público sino en los espectadores iniciados. Pero sí que la manera de programar satisfaga la vocación incluyente de las muestras nacionales desde que José Solé las implementara hace 28 años.

Justamente en este rango de los espectáculos de corta duración, si bien en la modalidad de una suerte de maratón o tanda de cinco obras por un solo boleto, tuvimos oportunidad de ver lo que desde mi perspectiva resultó lo más relevante de la Muestra de Zacatecas. A pesar de la incomodidad que sufrimos por espacio de seis horas consecutivas, destacaron Zootanos del defeño grupo Luna Avante, con el inveterado asunto del incesto entre hermanos como tema central; No tocar, de Teatro Cardinal de Querétaro, que trata con acierto el escabroso tema del abuso infantil; y por encima de todas, segunda ocasión consecutiva en el máximo evento nacional luego del éxito de Asalto al agua transparente en la Muestra de Pachuca 2006: En el mismo barco, que Lagartijas tiradas al sol, el conjunto artístico de Gabino Rodríguez y Luisa Pardo, pone al servicio del dilema juvenil frente a una realidad que avasalla sus débiles opciones de realización personal y social. Dicho maratón es una estrategia que merece perfeccionarse en las próximas 
emisiones de la Muestra y que, corregida y aumentada, aparte de dar cabida a mayor número de obras participantes, puede propiciar el advenimiento de nuevas estructuras dramáticas, acordes a la distinta percepción del mundo que tienen ahora los espectadores del siglo veintiuno.

Salve, por ahora, a los organizadores de la XXIX Muestra Nacional de Teatro 2008 en Ciudad Juárez, iganaron la rifa del tigre! Si bien cuentan con los mejores auspicios del Centro Cultural Paso del Norte y sus dos flamantes teatros: La gran sala "Víctor Hugo Rascón Banda" y la experimental "Octavio Trías," para revivificar el máximo evento dedicado a mostrar las expresiones escénicas de la provincia mexicana.

Universidad Juárez de Durango

Sistema Nacional de Creadores de Arte 